\title{
A Green and Cost-effective Approach to Reutilize the Effluent from Bleaching Process
}

\author{
${ }^{\mathrm{ab}}$ S. Saleemi, ${ }^{\mathrm{a} * Z}$ Z. A. Abro, ${ }^{\mathrm{c}}$ A. H Shah, ${ }^{\mathrm{d}}$ N. A. Rind, ${ }^{\mathrm{a}}$ A. Anwar, ${ }^{\mathrm{e}}$ A. W. Rajput \\ ${ }^{a}$ Key Laboratory of Textile Science \& Technology, Ministry of Education, College of Textiles, Donghua \\ University, 2999 North Renmin Road, Shanghai, 201620, China \\ ${ }^{b}$ Department of Textile Engineering and Technology, University of the Punjab, Lahore, Pakistan \\ ${ }^{\mathrm{c}}$ College of Material Sciences and Chemical Engineering, Harbin Engineering University, China \\ ${ }^{\mathrm{d}}$ Department of Textile Engineering,Mehran University of Engineering and Technology, Jamshoro, \\ Sindh, Pakistan \\ ${ }^{\mathrm{e}}$ Technical Textile Research Group, BZU College of Textile Engineering, Multan, Pakistan
}

\begin{abstract}
Environmental science and management is often the most discussed subject nowadays all over the world. In a number of countries, presently plenty of harms are associated with the effluent by industrial due to growing industrialization; this issue should be considered at large scale. Textile sector is one of the leading areas, which uses a high amount of chemicals and creating environmental pollution. Textile wet processing sector uses a lot of chemicals, surfactants and synthetic dyes, hence produce a large amount of wastewater having a high concentration of chemicals. This research is an effort to investigate the amount of residue remained in liquor after bleaching and reuses this liquor by adding a few chemicals according to the requirement. Afterward, the comparison was made between the bleached sample with fresh liquor and bleached sample with reused liquor. It was observed that bleaching with reused liquor shows good results though these results are insignificantly less than fresh bleaching liquor. On the other hand, fortunately, the color yield of dyed fabric bleached with reused liquor is higher than fresh liquor.
\end{abstract}

Keywords-Author should provide 3-5 relevant keywords

Date Received 09-07-2019

Date Accepted 25-12-2019

Date Published 31-12-2019

\section{INTRODUCTION}

Environmentally safety, cost-effective and energetically efficiency is nowadays under high consideration while treating the fabric with chemicals and water $[1,2]$. The textile industry is an important and rapidly developing industrial sector in Pakistan. The usage of different resources/ raw materials such as cotton, woolen, and synthetic fibers is very high in the textile area $[3,4]$. The consumption of water in wet processing sector is about three times than all the other departments [5]. The preparatory processes of wet processing department of textiles namely, desizing, scouring, bleaching, and washing are highly water and energy-consuming process [6,7]. This discharge wastewater contains chemicals like hydrogen peroxide, alkalis, acids, starch, dyes, dispersing agents and soaps of metals [8]. So, in terms of its ecological concerns, the textile industry is probably using more water than any other industry worldwide and almost all wastewater discharged are extremely contaminated $[9,10]$.
Bleaching is an essential process to get rid of natural colors and pigments from fabric to make fabric white and more absorbent. Previously, hypochlorite was widely used as a bleaching agent. Currently, hypochlorite is replaced by other bleaching agents such as sodium perborate and $\mathrm{H}_{2} \mathrm{O}_{2} . \mathrm{H}_{2} \mathrm{O}_{2}$ is an environmentally friendly alternative to hypochlorite bleaching agent. Higher luster along with less yarn destruction of the processed fabric is the one major benefits of $\mathrm{H}_{2} \mathrm{O}_{2}[11,12]$.

Numerous researches were done on the enhancement of machines/techniques to minimize the consumption of chemical and water [13,14], biotechnology applications, application of green chemicals, quality control and inventory management and others have been made to minimize chemical and water consumptions. One similar research recently has studied the reusing and the recycling of wastewater from textile dyeing industry [15]. Recently, simultaneous recovery of hydrogen and chlorine from industrial waste dilute hydrochloric acid have been studied [16]. In addition, the prediction of biological wastewater treatment process behavior via network model has also been studied recently [17]. These studies suggest the importance of waste treatment for the sustainable development of industries. 
This research is an effort to minimize the use of chemicals and water by reusing the waste liquor of exhaust and continuous bleaching process. Afterward, the key properties such as Berger Whiteness \%, absorbency, and tegwa rating and starch content were evaluated. This bleached fabric was further dyed by dyes to assess the effect of reusing bleaching liquor on the succeeding process of dyeing.

\section{MATERIALS AND METHODS}

\section{A. Materials}

Desized, plain weave $100 \%$ pure cotton fabric with 76 ends/inch and 68 picks/inch having 30 Tex warp and weft count was used in this work which was supplied by Popular Textile Limited, Karachi. Hydrogen peroxide, sodium hydroxide, stabilizer, wetting agent, sequestering agents, and Drimarene Reactive Blue-BR were supplied by Clariant, Pakistan, used directly as received without alteration.

\section{B. Exhaust Method}

In this study, all chemicals were mixed in water (for preparation of solution) having 1:20 liquor ratio for exhaust process as given in Table 1 . Fabrics were treated at $90^{\circ} \mathrm{C}$ for 25 minutes. Treated samples were hot rinsed at $80^{\circ} \mathrm{C}$ for 5 minutes then cold rinsed for 5 minutes. After rinsing, samples were dried through tumble dryer. The proposed model for exhaust bleaching machine is shown in Figure 1.

For Liquor Recovery: In High-Temperature Dyeing machine, used liquor remains present in the pot. In this research, after the first treatment, the pots were cooled down and the remaining liquor was collected. Then liquor was reused for further processing.

Fabric Treatment with Recovered Liquor: In order to assess the efficiency of recycled liquor, the pristine fabrics were treated with the recovered liquor according to the number of ingredients predicted by titration process.

\section{Continuous Method}

In this study, the laboratory scale pneumatic pressure vertical padding machine was used for experiments, see. A single recipe was used to treat the sample and afterward that liquor was reused. The proposed model for continuous bleaching machine is shown in Figure 2.

1) Fabric Treatment:Quantities of ingredients were measured according to the recipe as is shown (see Table 1). All the ingredients were mixed well and then the virgin liquor was poured on the upper side of vertical padder. For this study, $75 \%$ pickup percentage of padding mangle was set. All the fabric samples were treated with one dip nipping, and then oven dried at $100{ }^{\circ} \mathrm{C}$ for 10 minutes.

2) For Liquor Recovery: In this study, tray pot was placed on the bottom side of vertical padders. Drainage jaws of padders were opened by reducing pneumatic pressure, and then the liquor was collected in tray pot.

3) Fabric Treatment with Recovered Liquor: After evaluation of residual chemicals presents in liquor, it was found that some amount of ingredients remains present in used liquor. The amounts of these ingredients were calculated by titration method. Calculated ingredients were added into used liquor and used it for further treatments. Procedure for solomatic bleaching is same as mention above.

Table 1:Recipes for Solomatic Bleaching Process

\begin{tabular}{ccccc}
\hline & RCP1 & RCP2 & RCP3 & Cont. \\
\hline $\mathrm{H}_{2} \mathrm{O}_{2}$ & $6 \%$ & $8 \%$ & $16 \%$ & $\begin{array}{c}32 \\
\mathrm{ml} / \mathrm{l}\end{array}$ \\
$\mathrm{NaOH}\left(48 \mathrm{Be}^{\circ}\right)$ & $4.8 \%$ & $7 \%$ & $14 \%$ & $\begin{array}{c}28 \\
\mathrm{ml} / 1\end{array}$ \\
Stabilizer & $1.2 \%$ & $1.75 \%$ & $3.5 \%$ & $5 \mathrm{ml} / 1$ \\
Wetting Agent & $0.3 \%$ & $0.35 \%$ & $0.7 \%$ & $4 \mathrm{ml} / \mathrm{l}$ \\
Sequestering Agent & $0.12 \%$ & $0.17 \%$ & $3.5 \%$ & $5 \mathrm{ml} / \mathrm{l}$ \\
\hline
\end{tabular}

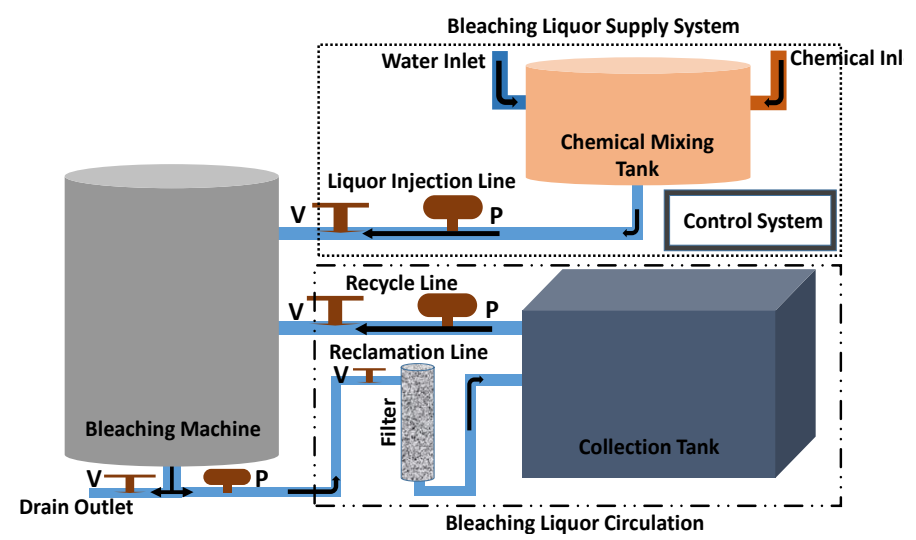

Figure 1:Proposed Model for Exhaust Bleaching Machine

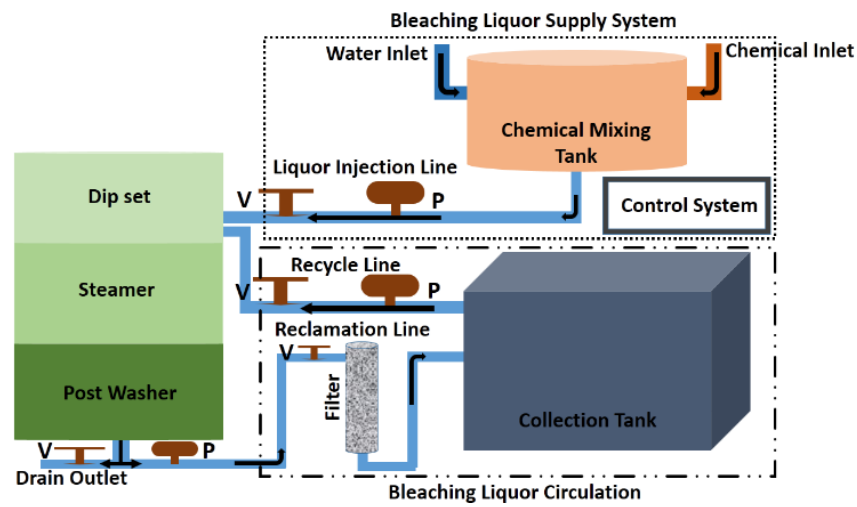

Figure 2: Proposed Model for Continuous Bleaching Machine 


\section{Dyeing of Bleached Samples}

Cotton fabrics bleached with fresh liquor and reused liquor are dyed by (Drimarene Reactive Blue-BR) on Padder machine. Fabric pieces were padded (70\% pickup, Benz padder) with an aqueous dye bath having $30 \mathrm{~g} / 1$ dye, $1 \mathrm{~g} / 1$ wetting agent and 15 $\mathrm{g} / \mathrm{l} \mathrm{Na} 2 \mathrm{CO} 3$. The padded fabric pieces were then subjected to drying at $1200^{\circ} \mathrm{C}$ for one minute in the drying oven. These samples were further cured at $1500^{\circ} \mathrm{C}$ for 1 minute. The fabric samples were then washed according to the method recommended by Clariant\&Schönberger and Schäfer[18], and at last, dried in an oven.

\section{E. Characterization}

The treated and untreated fabrics were subjected to Absorbency test (capillary rise method) and Tegwa scale rating (shows starch contents). Burger whiteness and K/S values were also obtained by data color spectrophotometer. The amount of $\mathrm{H}_{2} \mathrm{O}_{2}$, $\mathrm{NaOH}$, stabilizer, wetting, and sequestering agent remained in liquor assessed by titration method.

\section{RESULTS AND DISCUSSION}

In the exhaust method, fabrics were treated by three different recipes whereas in a continuous method contains only one recipe with fresh and reused liquor, the result of the different test are as under.

\section{A. Absorbency Test}

The Absorbency test of the desized and bleached sample is presented in Figure 3. It was clearly observed from the graph that absorbency is increased by increasing the concentration of bleaching agents in recipes. Absorbency test was carried by capillary rise method. The desized fabric has many impurities such as starch, waxes, pectin etc. Due to these impurities, the fabric possesses poor affinity to absorb water. Recipe-3 of exhaust method contains a high amount of ingredients, for this reason, it has high absorbance values. It can be observed clearly from the results that the absorbancy of the sample treated with reused liquor is also increased in comparison with desized fabric. However, this increase is insignificantly less than fresh liquor with the difference of 0.5 in RCP1 and 0.25 in RCP2, RCP3 and continuous method.

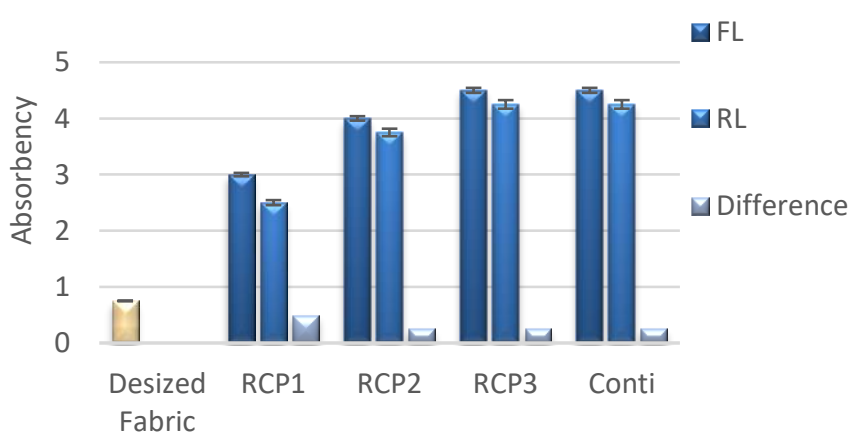

Different Bleaching Recipes

Figure 3: Comparison of the results from the absorbency test.

\section{B. Berger Whiteness}

By removing chlorophyll and xanthophyll, the whiteness of cotton fabric increases. $\mathrm{H}_{2} \mathrm{O}_{2}$ is used as a bleaching agent which can effectively remove these impurities $[11,12]$. In comparison with desized fabric, all treated fabrics have high values of Berger whiteness in both continuous and exhaust methods. Figure 4, demonstrates that using waste liquor (adding fresh chemicals in less quantity) also provide good results, although these values are insignificantly lower than a fresh one. It can be seen in Figure 4 that the difference between FL and RL is 3.7, 2.5, 1.9 and 2.9 for RCP1, RCP2, RCP3 and Continuous Method respectively.

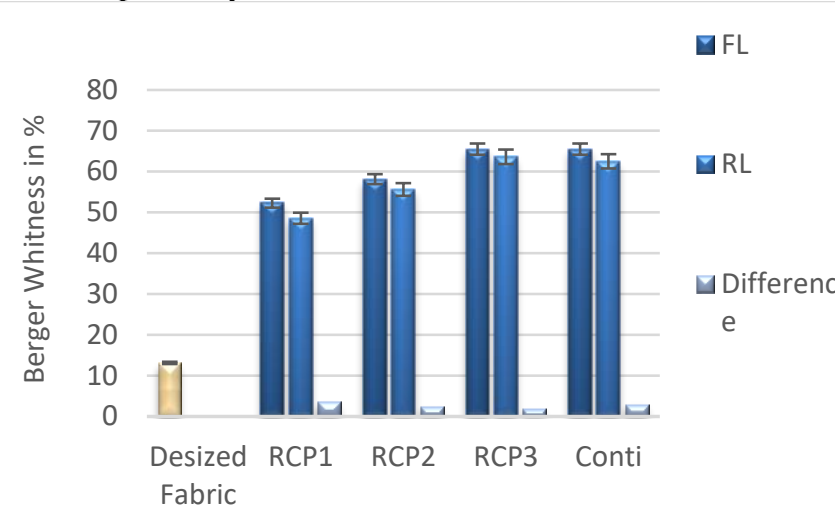

Different Bleaching Recipes

Figure 4: Comparison of the Berger Whiteness of the fabrics

\section{Color Strength (K/S Values)}

It can be seen in Figure 5 that Color strength K/S values. K/S is the Kubelka-Munk relationship, where $\mathrm{K}$ is an absorption coefficient and $\mathrm{S}$ is a scattering coefficient. This relationship is applied to textiles under the assumption that light scattering is due to the fibers while adsorption of light is due to the colorant. $\mathrm{K} / \mathrm{S}$ values are slightly higher on fabrics treated by reused liquor as compared to the fresh liquor in both cases: exhaust and continuous methods.

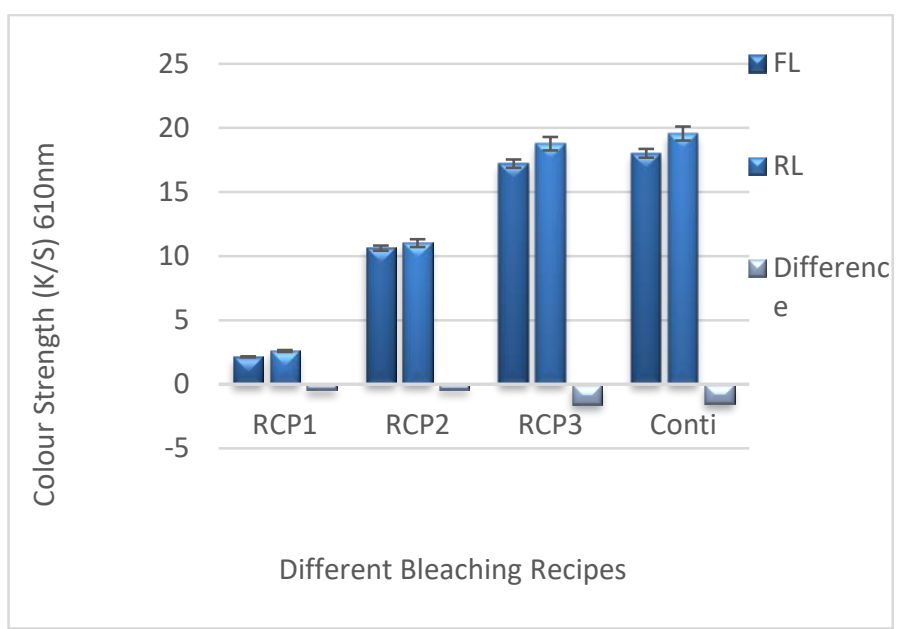

Figure 5: Comparison of the color strength of the fabrics 
This shows that bleaching with reused liquor enhances the color depth of fabric without changing its tone. It is because of slightly less burger whiteness of samples. The Difference in a negative value shows that reused liquor has a higher value of color strength as compare to fresh liquor. This difference is high in case of RCP3 and Continuous Method i.e. -1.56 and -1.54 respectively.

\section{Tegwa Rating \& Starch Contents}

In this research, Iodine solution staining on fabric is used to assess Tegwa violet scale rating. This rating used to indicate starch content. After desizing, 0.6-1\% starch remains in the fabric which is removed in further processing. Tegwa rating tends to move from 4 to 5 rating to $7 / 8$ rating which shows that unwanted starch is removing from the sample as the concentration of bleaching agents was increased (see Table 2). An obvious decrease in starch content percentage was found, from $0.6-1 \%$ to $0.06-0.08$ while using reused liquor.

Table 2: Rating of Tegwa Rating (TR) \& Starch Content\% (SC)

\begin{tabular}{cccccccccc}
\hline & \multicolumn{2}{c}{$\mathrm{RCP} 1$} & \multicolumn{2}{c}{$\mathrm{RCP} 2$} & \multicolumn{2}{c}{$\mathrm{RCP3}$} & \multicolumn{3}{c}{$\begin{array}{c}\text { Continuou } \\
\text { s Method }\end{array}$} \\
\hline & $\mathrm{FL}$ & $\mathrm{RL}$ & $\mathrm{FL}$ & $\mathrm{RL}$ & $\mathrm{FL}$ & $\mathrm{RL}$ & $\mathrm{FL}$ & $\mathrm{RL}$ \\
Tegwa & $4 /$ & $3 /$ & $5 /$ & $4 /$ & $7 / 8$ & $6 / 7$ & $7 / 8$ & $6 / 7$ \\
Rating & 5 & 4 & 6 & 5 & & & & \\
Starch & 0.3 & 0.6 & 0.2 & 0.3 & 0.0 & 0.06 & 0.0 & 0.1 \\
Conten & - & - & - & - & $5-$ & - & $8-$ & $2-$ \\
$\mathrm{t}$ & 0.2 & 0.3 & 0.1 & 0.2 & 0.0 & $\mathrm{~s} 0.0$ & 0.0 & 0.0 \\
& & & & & 6 & 8 & 6 & 8 \\
\hline
\end{tabular}

\section{E. Liquor Assessment}

Exhaust method contains a high amount of waste because of having a high liquor ratio and a high percentage of chemicals. Having a large amount of water in it so, other chemicals are added accordingly. It also has a high amount of residual chemicals to recover liquor. In the continuous method, padding trough contains a low amount of water and chemicals. Due to which recover liquor has a low amount of residual chemicals. The amount $\mathrm{H}_{2} \mathrm{O}_{2}$ and $\mathrm{NaOH}$ of residuals remain in liquor are calculated by titration methods by given formulae, as shown in Equation 1 and Equation 2.

$\% \mathrm{H}_{2} \mathrm{O}_{2}=\frac{\text { KMnO4 consumed } \times \text { Normality of KMnO4 } \times \text { Equivalent wt: of } H 2 O 2 \times 100}{\text { wt: of sample } \times 1000} \%$

$\mathrm{NaOH}=\frac{H 2 \text { SO4consumed } \times \text { Normality of } H 2 S O 4 \times \text { Equivalent wt: of } \mathrm{NaOH} \times 100}{\text { wt: of sample } \times 1000}$

Figure 6 (a) shows the amount of hydrogen peroxide in fresh and recover liquors and amount of added hydrogen peroxide in it. Due to padding trough volume, a low amount of residual chemicals recovers in a continuous process. Figure 6(b) shows amounts of sodium hydroxide in fresh and recovers liquors and also added an amount for reprocessing the liquor

It can clearly be observed in Figure 6 that reuse liquor has a valuable chemical. If chemicals are drained, it's loose of not only money but it leads to an imbalance in the environment. To reduce the cost and environmental impact these wasted chemicals were able to reuse by added a small quantity than reused in the same bleaching process. By doing this not only the cost of new chemicals saved but also the impact on the environment is significantly reduced.

The textile wastewater has a high conductivity, salt (Total Dissolved Solids, TDS) and Hardness load, which are not readily amenable to biological treatment. However, these impurities in waste lead to an imbalance in the environment but if residue then these are very expensive chemicals for bleaching process. Qualities of exhaust and continuous method liquors were assessed in terms of conductivity, TDS (total dissolved solids) and hardness. $\mathrm{pH}$ of all liquors was same i.e. 10-11 due to use of a stabilizer. Figure 7 show TDS, conductivity and hardness accordingly.
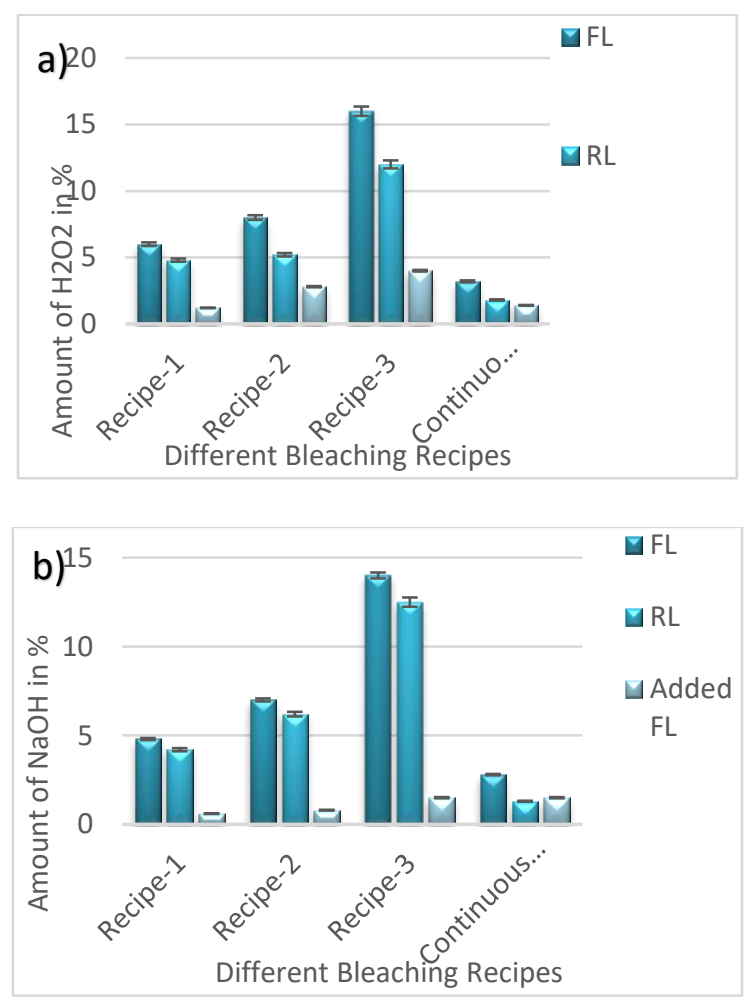

Figure 6: (a) Amount of $\mathrm{H}_{2} \mathrm{O}_{2}$ in Liquor (b) Amount of $\mathrm{NaOH}$ in Liquor

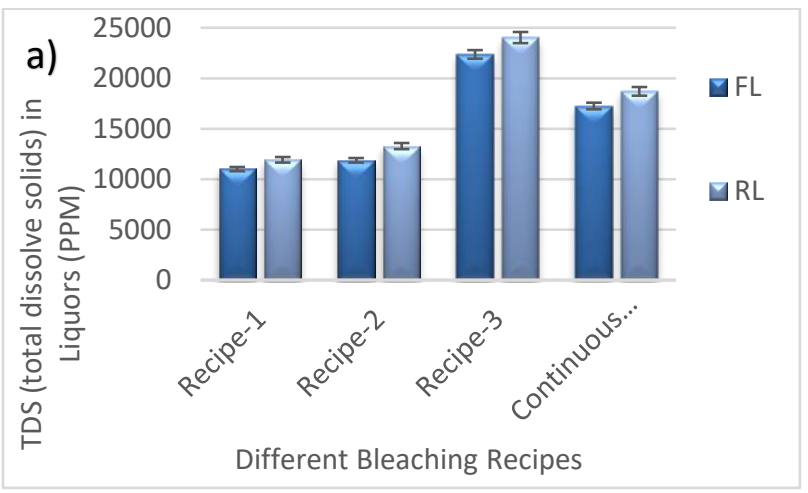



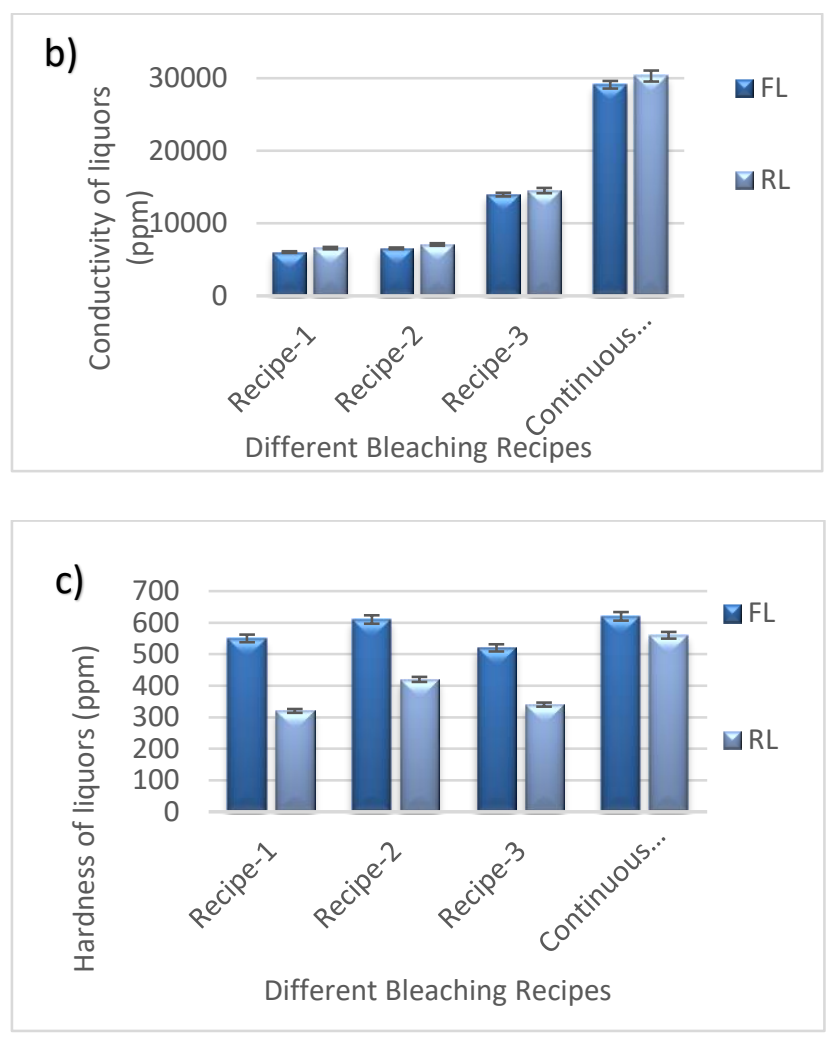

Figure 7: (a) Conductivity of liquors (ppm) (b) TDS (total dissolved solids) in Liquors (c) Hardness of Liquors

It can be depicted that from Figure 7(b) that there is a slight increase in TDS value in PPM as in reused liquor (RL) there is a higher amount of chemicals the chemicals remain in fresh and the chemical added for bleaching it again. The insignificant change was found in the conductivity of fresh liquor and reused liquor. However, the hardness of liquor is reduced by using the discharged liquor that is a positive sign that the liquor which is drained contain fewer hardness particles as these particles were utilized by re-bleaching.

\section{F. Conclusions}

The textile industry in developing countries is hardly endeavoring due to many problems i.e. high costs of raw materials and energy, shortage of energy, environmental legislation, and laws. These issues have made difficult for the textile industry to survive in the international and local markets. It was observed that by reusing the remaining liquor and adding a small quantity of these chemicals, acceptable results are found. It was found that good color strength was achieved by using reused liquor. This research concluded that remaining liquor of batch and continuous process is still useful, which reduced the amount of chemical and water consumption in bleaching. It was observed that almost the same absorbency, insignificantly less Berger Whiteness\% but improved color strength was achieved. It was found that reused liquor has less hardness, with the same conductivity and slightly higher TDS in waste liquor proves that this is an economic and ecological approach for the textile industry. To optimize the Berger whiteness of bleach fabric and color yield of dyed fabric, further optimization of the bleaching recipe is needed in order to save the environment and cost.

\section{Data AVAILABILITY}

All the data is available on request by writing an email to the main corresponding author.

\section{CONFLICTS OF INTEREST}

The authors declare that there is no conflict of interest regarding the publication of this paper.

\section{FUNDING STATEMENT}

There was no external funding received for this research.

\section{ACKNOWLEDGMENTS}

The authors would like to acknowledge all the laboratory staff of Donghua University, China.

\section{REFERENCES}

A. El Shafie, M. M. Fouda, and M. Hashem, "One-step process for bio-scouring and peracetic acid bleaching of cotton fabric," Carbohydrate polymers, vol. 78, no. 2, pp. 302-308, 2009.

[2] A. Khatri, H. Memon, Z. U. N. Bhatti, S. Qureshi, and F. Zaib, Reducing the Effluent Pollution by Using Trisodium Nitrilotriacetate in Batch Process of Dyeing Cotton Fabric with Fiber-Reactive Dyes. Springer Singapore, 2014, pp. 107-111.

[3] C. R. Holkar, A. J. Jadhav, D. V. Pinjari, N. M. Mahamuni, and A. B. Pandit, "A critical review on textile wastewater treatments: possible approaches," Journal of environmental management, vol. 182, pp. 351-366, 2016.

[4] H. Memon, H. Wang, and E. Langat, "Determination and Characterization of the Wool Fiber Yield of Kenyan Sheep Breeds: An Economically Sustainable Practical Approach for Kenya," Fibers, vol. 6, no. 3, p. 55, 2018.

[5] R. E. Brooks and S. B. Moore, "Alkaline hydrogen peroxide bleaching of cellulose," Cellulose, vol. 7, no. 3, pp. 263-286, 2000.

[6] A. Khoso, H. Memon, M. Hussain, A. Sanbhal, and A. Abro, "Production and Characterization of Wool and Hair Fibers in Highlands of Baluchistan, an Economic and Sustainable Approach for Pakistan," in Key Engineering Materials, 2016, vol. 671, pp. 473-482: Trans Tech Publ.

[7] H. Memon, A. Khatri, N. Ali, and S. Memon, "Dyeing Recipe Optimization for Eco-Friendly Dyeing and Mechanical Property Analysis of Eco-Friendly Dyed Cotton Fabric: Better Fixation, Strength, and Color Yield by Biodegradable Salts," Journal of Natural Fibers, vol. 13, no. 6, pp. 749-758, 2016. 
[8] S. Paul, S. Chavan, and S. Khambe, "Studies on characterization of textile industrial waste water in Solapur city," International Journal of Chemical Sciences, vol. 10, no. 2, pp. 635-642, 2012.

[9] P. C. Vandevivere, R. Bianchi, and W. Verstraete, "Treatment and reuse of wastewater from the textile wet-processing industry: Review of emerging technologies," Journal of Chemical Technology \& Biotechnology: International Research in Process, Environmental AND Clean Technology, vol. 72, no. 4, pp. 289-302, 1998.

[10] R. Kant, "Textile dyeing industry an environmental hazard," Natural science, vol. 4, no. 1, pp. 22-26, 2012.

[11] E. Abdel-Halim and S. S. Al-Deyab, "One-step bleaching process for cotton fabrics using activated hydrogen peroxide," Carbohydrate polymers, vol. 92, no. 2, pp. 1844-1849, 2013.

[12] T. Liang and L. Wang, "An environmentally safe and nondestructive process for bleaching birch veneer with peracetic acid," Journal of Cleaner Production, vol. 92, pp. 37-43, 2015.

[13] A. M. Kocabas, H. Yukseler, F. B. Dilek, and U. Yetis, "Adoption of European Union's IPPC Directive to a textile mill: Analysis of water and energy consumption," Journal of environmental management, vol. 91, no. 1, pp. 102-113, 2009.

[14] S. Pfister, A. Koehler, and S. Hellweg, "Assessing the environmental impacts of freshwater consumption in LCA," Environmental science \& technology, vol. 43, no. 11, pp. 4098-4104, 2009.

[15] X. Lu, L. Liu, R. Liu, and J. Chen, "Textile wastewater reuse as an alternative water source for dyeing and finishing processes: A case study," Desalination, vol. 258, no. 1-3, pp. 229-232, 2010.

[16] N. Paidimarri, U. Virendra, and S. Vedantam, "Simultaneous Recovery of Hydrogen and Chlorine from Industrial Waste Dilute Hydrochloric Acid," International Journal of Chemical Engineering, vol. 2016, 2016.

[17] Y. Sanayei, N. Chaibakhsh, A. Chaibakhsh, A. R. Pendashteh, N. Ismail, and T. T. Teng, "Long-Term Prediction of Biological Wastewater Treatment Process Behavior via Wiener-Laguerre Network Model," International Journal of Chemical Engineering, vol. 2014, 2014.

[18] H. Schönberger and T. Schäfer, "Best available techniques in textile industry," Berlin: Federal Environmental Agency, 2003.

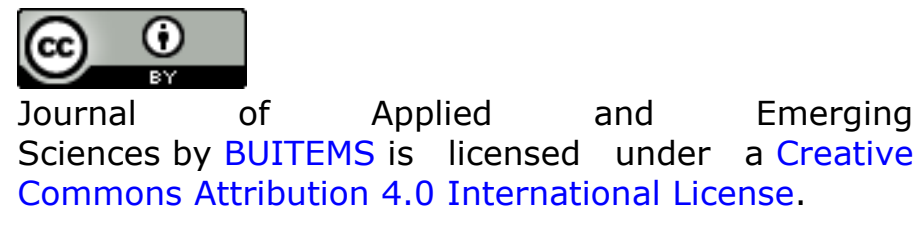

